Orality and Markedness

Author(s): Donca Steriade

Proceedings of the Nineteenth Annual Meeting of the Berkeley Linguistics

Society: General Session and Parasession on Semantic Typology and

Semantic Universals (1993), pp. 334-347

Please see "How to cite" in the online sidebar for full citation information.

Please contact BLS regarding any further use of this work. BLS retains copyright for both print and screen forms of the publication. BLS may be contacted via http://linguistics.berkeley.edu/bls/.

The Annual Proceedings of the Berkeley Linguistics Society is published online via eLanguage, the Linguistic Society of America's digital publishing platform. 


\section{Orality and markedness}

\section{Donca Steriade}

$U C L A$

\section{Introduction}

Most of the phenomena discussed in this paper involve the realization of a nasal stop as a pre- or postnasal $\left(\mathrm{mb}_{\mathrm{b}}\right.$ or $\left.\mathrm{b}^{\mathrm{m}}\right)$ in the environment of oral vowels. Thus Guarani nasals are reported as postoralized before oral vowels (1), whereas Land Dayak nasals are transcribed as preoralized when they follow oral vowels (2).

(1) Postoralization: $\mathrm{ma} \rightarrow \mathrm{m}_{\mathrm{ba}}$ (contrast mã , which remains mã.)
(2) Preoralization: $a m \rightarrow a b^{m}$ (contrast ãm, which remains ãm.)

My interest in this class of processes stems from the fact that both preoralization and postoralization are usually viewed as assimilatory phenomena: the stops appear to acquire the orality of the neighboring vowel. For there to be assimilation in such cases, we would have to assume that the feature [nasal] is binary, in the sense that a segment's orality is phonologically represented.

(3) a. An assimilatory analysis of postoralization:

spread [-nasal] from vowel onto preceding nasal C.

b. An assimilatory analysis of preoralization:

spread [-nasal] from vowel onto following nasal $\mathrm{C}$.

Yet there are good reasons to assume that [nasal] is a privative feature, in the sense that oral segments are distinguished from their nasal counterparts simply in terms of the absence of [nasal]. In fact, when we enumerate the relevant arguments, it appears that pre- and postoralization are the only welldocumented phenomena that stand between us and a successful privative analysis of nasality. I intend to show that neither of these processes is best analyzed as assimilatory: neither requires manipulating orality. We will conclude that nasal can - indeed must - be a single-valued feature.

What is the connection between privative nasality and markedness? [Nasal] belongs to a larger class of features which display context-free markedness: by which I mean that their cross-linguistic distribution is such that they lend themselves to the formulation of context-free implicational universals of the type shown in (4):

(4) a. If a language possesses a [+nasal] series of sounds then it will possess the corresponding [-nasal] series.

b. If a language possesses a [+spread] series of sounds then it will possess the corresponding [-spread] series.

c. If a language possesses a [+constricted] series of sounds then it will possess the corresponding [-constricted] series.

It will be my suggestion that the features listed in (4) are all singlevalued; and, more generally, that only features for which markedness statements such as those given in (4) are universally defensible should be considered singlevalued. A substantial number of other features appear to pattern in very 
different ways, in the sense that no cross-linguistic context-free tendency can be observed for one of their values to imply the other. The last part of this paper will contain some speculations on the reasons why such a contrast might exist between seemingly binary and seemingly single-valued features.

\section{An overview of the phonological uses of [-nasal]}

If we inventory the phonological uses of the specification [-nasal], the list will include the following structures and processes:

(5) Conceivable uses of [-nasal]

a. Nasal contours : [+nas][-nas] $\left(\mathrm{m}_{\mathrm{b}}\right)$ or $[-$ nas $][+$ nas $]\left(\mathrm{b}^{\mathrm{m}}\right)$
b. Blocking [nasal] harmony:

[-nas] morph blocks spreading from [+nas] morph.

c. Assimilatory postoralization: ma $\rightarrow$ mba. [-nas] spreads leftward locally.

d. Assimilatory preoralization: am $\rightarrow$ abm. [-nas] spreads rightward locally.

Interestingly, among the candidate analyses making use of [-nasal] values, we do not encounter long-distance oralization harmonies: no language known to me can be shown to spread the orality of some segment class onto a longer span (as imagined in (6)). Nor do we encounter oral disharmonies: no language I have seen described disallows the cooccurrence of oral segments, within any domain, at close range or distantly. An imaginary case of this type is
outlined in (7).

(6) Non uses of [-nasal]: unbounded/ non-local harmony

i. Fictive Guarani: all segments, including $\mathrm{m}, \mathrm{n}$, become fully oral before stressed oral vowel.

ii. Contrast real Guarani (Rivas 1975, Kiparsky 1985): m,n maintain at least partial nasality before oral V: amá -> ambá .

(7) Non-uses of [-nasal]: disharmony requires [ $\alpha$ nasal] [- $\alpha$ nasal]

i. Fictive Mazateco: *nã and *ta are disallowed but tã, na ok.

ii. Contrast real Mazateco (Pike and Pike 1947): *nã, but ok ta, tã, na.

Both the unattested orality harmony (6.i) and the unattested orality disharmony (7.i) are to be compared with the widely attested harmony and disharmony processes involving [+nasal]. The obvious question is: why should [nasal] be underutilized in these ways? The only answer that seems fully satisfying is that oral segments do not carry [-nasal] specifications: [nasal] is privative, as anticipated by Trubetzkoy (1939) <1>. If [-nasal] does not exist, it cannot spread or dissimilate. This interpretation requires some reanalysis of the phenomena listed in (5) and answers to a more basic question: why does phonetic orality lack a phonological counterpart in the form of a [-nasal] value?

\section{Nasal contours}

Let's begin then by taking a second look at the phenomena in (5). I would like to first briefly dispose of the first two - nasal contours and oral blockers. The subject of distinctive nasal contours was taken up in Steriade (1993) where it is shown that they should be analyzed as released plosives, whose closure and release are separately represented. (The relevance of the closure/release distinction in phonology was also signalled by Kingston 1985). Nasality can be realized on closure (in the case of prenasals), on release (in the case of postnasals) or on both positions (for fully nasal stops). The notation below 
involves the following elements: closure (or aperture zero) abbreviated as $\mathrm{A}_{0}$, and approximant release (or maximal aperture) abbreviated as $A_{\max }$. These definitions of aperture positions are inspired by Ladefoged (1971) and have been defended in greater detail elsewhere:

$$
\begin{gathered}
\text { nasal stop } \\
\hline \text { nas] } \\
\text { A } \\
\mathrm{A}_{0} \mathrm{~A}_{\max }
\end{gathered}
$$

$[\mathrm{m}]$

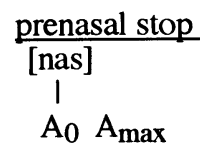

[mb] postnasal stop
$[$ nas]
A $_{0} \mathrm{~A}_{\max }$

$\left[\mathrm{b}^{\mathrm{m}}\right]$

In support of the structures in (8), I note that the possibility of contours disappears when the segment is a continuant (because continuants lack the segment internal discontinuity that justifies the closure/release distinction in plosives) or when the plosive is unreleased (because an unreleased stop has just closure, $\mathrm{A}_{0}$ ). The representations in (8) show that this closure/release distinction allows us to have distinct structures for fully and partially nasal segments without using [-nasal].

\section{Oral blockers}

Consider now the phenomenon of oral blockers in nasal harmony processes. A subset of the relevant cases has been analyzed by Cole (1987) and Pulleyblank (ms.): these are cases in which a voiceless segment blocks both the association and the subsequent spreading of nasality. Cole and Pulleyblank suggest that such cases do not require that the voiceless segments be specified [-nasal], but only that the relevant nasal harmony processes be limited to apply between strictly adjacent segments: non-undergoers will then necessarily become blockers, whether or not they carry a phonological mark of orality. This scenario can be exemplified using the Terena data below (from Bendor-Samuel 1966):

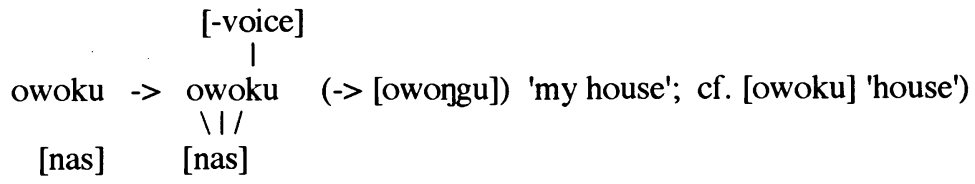

Blockage of nasality spreading beyond $\underline{\mathrm{k}}$ is due to (a) the cooccurrence filter * [+nasal, -voice] and (b) to the fact that spreading must be strictly local.

Blockers of this type may involve any segments possessing a feature that is incompatible with the optimal realization or perception of nasality: consonantal continuants (cf. Ohala 1975, Poser 1981, Cohn 1993), laterals, voiceless segments. It is the incompatibility betwen nasality and these other features that arrests the spreading, not - or not necessarily - the presence of a [-nasal] value.

A more challenging case is that of oral morphemes which appear to idiosyncratically block the unbounded spread of nasality in certain languauges. The cases I have in mind involve Tucanoan languages - Desano and Tatuyó - that have been discussed in this context by Kaye (1971) and Gomez-Imbert (1980). Both languages are described as dividing their morphemes into four categories: 
(10) Morphemes of Eastern Tucanoan (after Gomez Imbert 1980)

class A: [+nasal, +nasalizing]:

class B: [+nasal, -nasalizing]

class C: [-nasal, +nasalizable]

class D: [-nasal, -nasalizable]

The dominant classes A,D tend to be stems, roots, and content morphemes: "les lexèmes appartiennent, à quelques exceptions près, au classes A et D, les classes fortes: autrement dit, les éléments léxématiques sont déterminants pour l'harmonie nasale dans le mot." (Gomez-Imbert 1980:79). Lexical classifiers may also belong to classes A-D. Class B consists of nasal affixes: they fail to have a nasalizing effect on adjacent oral stems. Class $C$ consists of oral affixes: these regularly become nasal next to a class $\mathrm{A}$ morpheme. The two recessive classes, $\mathrm{B}$ and $\mathrm{C}$, are thus function morphemes: [there is] "convergence entre grammème et propriété nasale/non-nasale faible." (Gomez-Imbert 1980: 82). They are not tonally specified, in contrast to morphemes belonging to classes A, D. Kaye and Gomez-Imbert (1980, 1993 per litt.) analyze class D as possessing [nasal] specifications. Tatuyo examples of the data this classification is meant to describe are given below. Morphemic nasality is indicated as a preposed tilde:

(11) Morpheme combinations in Tatuyó (Gomez-Imbert 1980, and 1993 p.c.)

(i) A + C: kedoo - bi $\rightarrow$ kẽnnõõmi

make $1 \mathrm{sg}$

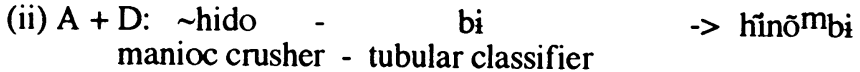

(iii) $\mathrm{C}+\mathrm{C}+\mathrm{A}+\mathrm{D}+\mathrm{C}$ :

ki - ha - dodi - hoo - wi $\rightarrow$ kihãnõnihoowi

we incl. gave sent him

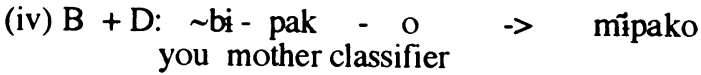

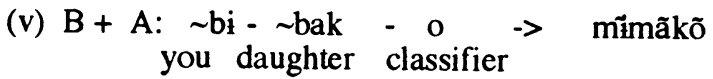

(vi) $\mathrm{C}+\mathrm{D}+\mathrm{C}+\mathrm{C}+\mathrm{B}$ :

ki - pak - i - re - - da $\rightarrow$ kipakirenã

he father class. object own

One is obviously tempted to analyze the distinction between the two oral classes - the recessive class $C$ and the dominant class D - as stemming from the presence or absence of a [-nasal] value. An analysis of mipako 'your mother' (11.iv above) along these lines would work as follows: nasal values would associate cyclically to their tautomorphemic segments, in such a way that all segments would be fully specified as [+nasal] or [-nasal] on the second cycle. This will preclude any spreading across morpheme boundaries:

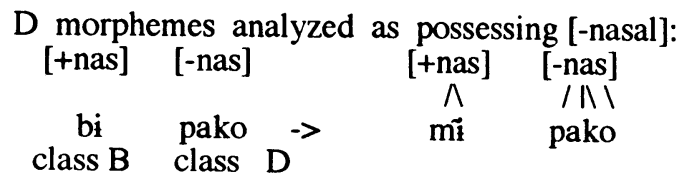


But this analysis takes no account of Gomez-Imbert's point about the correlations between morpheme class and spreading/blocking function. We should therefore consider the possibility of utilizing just the distinction between content and function morphemes - without recourse to a distinction between [nasal] and [0 nasal] - in accounting for the difference between oral undergoers (class C) and oral blockers (class D). Notice first that we must assume that function morphemes can be specified for the feature [nasal]: this conjunction of properties is what characterizes class B. Given this, the immediate question to ask is why there are no function morphemes that can be specified as [-nasal]: if there were any, we would have function morphemes that are invariably oral, i.e. belonged to class $\mathrm{D}$. The answer is that [-nasal] is not a phonological value and that nasality spreads from content morphemes to function morphemes: both content and function morphemes may be specified as [nasal] or unspecified, but only the lexemes, the content morphemes, may initiate spreading. There is perhaps a prosodic interpretation of this analysis: most function morphemes belong to the prosodic domain defined by an adjacent content morpheme and it is conceivable that nasality spreads within the prosodic domains thus defined. A proposal along these lines was recently made by Zsiga (1992), who succeeds in analyzing ATR harmony in Igbo without reference to the recessive [-ATR] value by relying on prosodic delimitation of the domain of harmonic spreading. For Tatuyó too this interpretation may be the most attractive one, but without additional restrictions it does not account for the fact that harmony takes place in $\mathrm{C}+\mathrm{A}, \mathrm{A}+\mathrm{C}$ combinations 11.(i) but not in $\mathrm{B}+\mathrm{D}, \mathrm{D}+\mathrm{C}+\mathrm{B}$ combinations (11.iv, 11 vi). At the very least we must add the condition that spreading may only be initiated by a content morpheme.

(13) An conjecture about morpheme class and nasality in Tatuyó:

a. Prosodic domains are defined by content morphemes (lexemes).

b. Function morphemes are incorporated into existing domains, without projecting their own.

c. [nasal] spreads within the domains thus defined, from content onto function morphemes.

(14) Examples (cf. 11.iii and vi). Bold characters indicate content morphemes.

(iii) $[\mathrm{C}+\mathrm{C}+\mathbf{A}]+[\mathrm{D}+\mathrm{C}]$

ki -ha $-\sim$ dodi - hoo - wi $\rightarrow$ kïhãnõníhoowi

we incl. gave sent him

(vi) $[\mathrm{C}+\mathrm{D}+\mathrm{C}+\mathrm{C}+\mathrm{B}]:$

ki - pak - i - re - da $\rightarrow$ kipakirenã

he father class. object own

Aside from the possibility of analyzing this data without recourse to [nasal], do we learn something more general from this discussion of oral blockers? What is significant in the case of Eastern Tucanoan is that the properties we were tempted to describe as due to [-nasal] specifications are not freely distributed within the lexicon: only content morphemes possess them. In contrast, nasality did turn out to have the wide distribution we expect of a true phonological feature, since both content and function morphemes possess it. Our analysis did justice to this contrast. It is not clear how an analysis relying on representing dominant orality as [-nasal] - along the lines of (12) - can do this. 


\section{Postoralization}

A much more common use of [-nasal] is the analysis of local postoralization first considered by Anderson (1976): in languages like Guaraní, voiced plosives are realized as prenasal before oral vowels and as fully nasal before nasal vowels. Anderson's interpretation of this fact, and that of subsequent writers - aside from Glynne Piggott and myself - has been that the nasals are basic and the prenasals derived by spreading the orality of the following vowel:

Guarani (Kiparsky 1985, Piggott 1992)

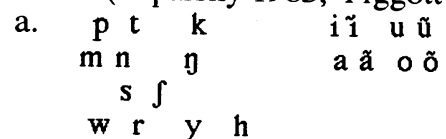

b. Iterative spreading leftwards: seretã- - [ [s̃ẽrẽtã-] 'country\}

no-ro-henui $\rightarrow$ [nỡõônẽ $n_{\text {dui] }}$ 'not hear'

c. Nasal stops are prenasal before oral : no-ro-haihui $\rightarrow$ [ $\mathrm{n}_{\text {dorohaihui }]}$

d. Stressed syllables arrest leftward spread:

ãmó-gwaré 'there-from' (*ãmbó-gwaré)

maré $\rightarrow$ [mbaré] 'thing'

õ-mã̃é-mbá 'they all looked' (*ơmba?é-mbá)

maRé $\rightarrow$ [mãẩ ] 'to see'

(16) Assimilatory postoralization (Rivas 1975 to Kiparsky 1985):

spread [-nas] from stressed $\mathrm{V}$ and [+nas] from $\mathrm{C}$ and stressed $\mathrm{V}$

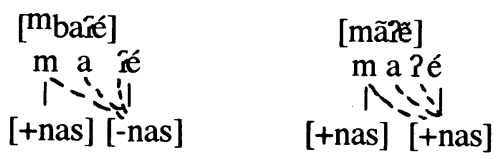

Several questions arise about the analysis in (16). The first, raised by

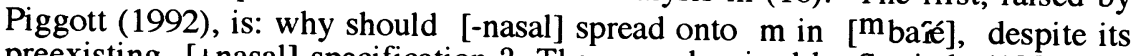
preexisting [+nasal] specification? The second, raised by Steriade (1993), is: why does [-nasal] fail to spread onto stressed õ in ãmô-gwaré ? Why don't we get a prenasalized vowel $\tilde{o}_{O}$ ?

To get an explanation, we turn again to the representations introduced earlier, in which stops are shown as having closure and release, while continuants - including vowels - have only one position. This is the analysis in (17). We will assume that the nasal series of Guaraní is underlyingly composed of voiced stops, realized with [nasal] on closure. Thus prenasals are the default realization of voiced stops, not the effect of orality assimilation. Full nasals result from the spread of nasality onto the release of the prenasals. Harmony is bound by the stress foot, as suggested by van der Hulst and Smith (1982), Flemming (1993).

UR:

$$
\begin{aligned}
& \text { - } \\
& \text { I } \\
& \text { [voi] }
\end{aligned}
$$

[mã?æ]

/bare/ 


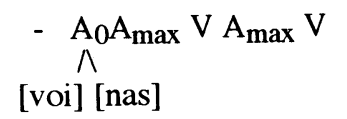
- $A_{0} A_{\max } V A_{\max } V$ $\Lambda$
[voi] [nas]

[mbaré]

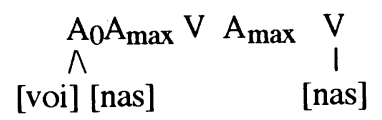

$A_{0} A_{\max } V A_{\max } \mathrm{V}$
[voi] [nas]

[mã?ẽ]

It should be noted here that although both the analysis I suggest in (17) and that in (16) characterize the central facts of Guaraní, they have rather different implications when we consider the details. In his 1985 paper on the connection between lexical phonology and underspecification theory, Kiparsky has considered the assumptions that allow one to claim that the oral vowels have a [-nasal] value to spread: what is at issue here is the fact that only stressed oral vowels appear to spread orality. The question is this: why do only the oral stressed vowels the have ability to spread orality? Why not some other oral segments? Kiparsky's answer - somewhat abbreviated - is that in Guaraní nasality is distinctive for vowels only and within stressed syllables only: this means that orality can be lexically specified in stressed vowels but nowhere else. Hence the only lexical sources for oral spreading will be the stressed vowels. What is puzzling, however, is that when we apply a similar logic to the stops we must conclude that the nasality of voiced stops (items like $\mathrm{m} / \mathrm{m} b$ ) is nondistinctive, since it can be predicted from their voicing. Hence it should be unavailable lexically and thus unable to spread, contrary to fact. Thus it is not possible to upheld consistently, within the framework of (16), the view that only distinctive nasality/orality spreads in Guaraní.

Aside from avoiding this conundrum, a distinct advantage of the analysis in (17) is the fact that it relies on a theory of representations that explains why nasal contours are impossible on continuants. Suppose now that one wanted to maintain an assimilatory analysis of postoralization but, at the same time, one tried to adopt the sort of representations that explain the questions about contours: could we adopt the aperture-based representations in (17) and still derive postoralization by spreading orality from a following vowel? The answer is no: a rule that derives the prenasals by spreading orality onto the release of a nasal stop will be feature-changing, when given an A-position analysis, as shown in (18). This will incorrectly entail that the same feature-changing rule might be able to apply and eliminate the nasality of vowels.
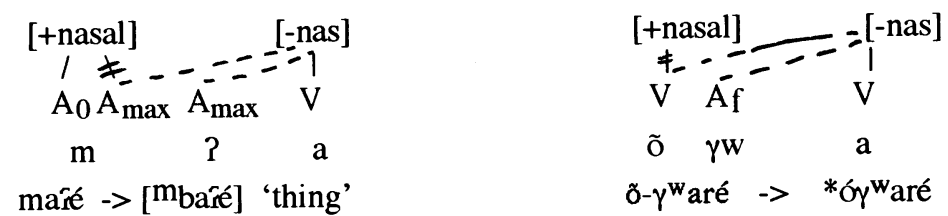

The conclusion is this. If we believe that prenasals derive from assimilatory postoralization, we can implement this idea only in a notational framework that cannot answer basic questions about the distribution of nasal contours. Once we abandon that framework, we have to abandon the notion that postoralization is assimilation. We have no choice in this case. 


\section{Preoralization}

Perhaps the most challenging phenomenon for a supporter of privative nasality is the existence of cases which look like the mirror-image of Guarani postoralization. This family of processes turns a fully nasal stop into a postnasal (or preoral) when preceded by an oral vowel. The best known instance of what looks like assimilatory preoralization is the Land Dayak process analyzed by Scott (1964) and later by Kenstowicz and Kisseberth (1978).

(19) Apparent assimilatory preoralization: $\mathrm{m} \rightarrow \mathrm{bm} / \mathrm{a}$

Land Dayak (Scott 1964, Kenstowicz and Kisseberth 1978)

a. Nasal harmony: mãlu 'strike', ums̃ 'water', nãbur 'sow, sijãũ 'cat'

b. Preoralization evidence: ntakadn 'taste', pəlabm 'mango', padagn 'field', tu?adn 'open' kinãm 'feeling' pimãin 'a game', pəmin 'dizzy', nũ?ãn 'open'

If preoralization is assimilation, then what spreads is orality. Viewed in these terms, the rule will have to be bled by nasal harmony:

$$
\begin{gathered}
\text { [-nas] } \\
\text { [+nas] } \\
\mathrm{V} \\
\mathrm{CH}
\end{gathered}
$$

A partial inventory of cases similar to Land Dayak has been made by Poser (1978). I hope to add a few new instances of preoralization here. But before we turn to a survey of these cases, I'd like to point out that the facts summarized in (19) can in principle lend themselves to a non-assimilatory analysis, which does not rely on [-nasal]. This is the analysis in (21), which assumes that word-final stops in Dayak are released.
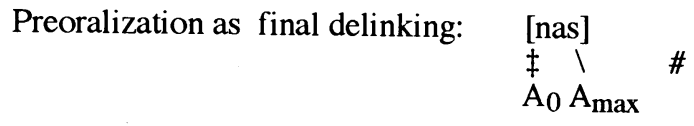

If we adopt (21), the perceived lack of preoralization in kinãm, pimãin etc. will be attributed to phonetic interpolation across the nasally unspecified closure (cf. Cohn 1990). The interesting question is therefore not whether we can do without [-nasal] in this case: (21) shows we can. Rather, we should ask whether anything is gained by doing so, in addition to upholding the more restrictive theory of privative nasality. In particular, we seek to understand the cross-linguistic properties of preoralization, which have not been investigated so far. A first issue raised by the Land Dayak data is: why do only final stops preoralize?

Some light is shed on this question when we observe that stress falls on the final in Land Dayak: "The position of maximum differentiation for consonantal phonemes is introducing the final syllable, and for vowels is the peak of the final syllable. " (Court 1967:203, on Mentu Land Dayak). No long vowels or mid vowels or laryngeals occur in prefinal syllables. These distributional facts suggest strongly that the final is stressed: it is typically the case that stressed syllables can anchor more features and more complex feature combinations than stressless ones. We have therefore two possible leads to investigate: one is the 
restriction of preoralization to final syllables; the other is its possible connection to stress.

The results of the cross linguistic survey begun by Poser, summarized in (22), support both the connection between preoralization and stress and its restriction to final syllables. Preoralizations are found in: Kendayan Dayak, Khmu? Halang, Mal, Semang Chewong, Stieng, some Thai dialects (for all the preceding: Poser 1978); and also in Diyari, Arabana, Lappish and Icelandic (discussed below)

(22) Cross-linguistic properties of preoralization:

a. Preoralization tends to apply in final syllables; and, when non-final, in stressed syllables only (Lappish, Icelandic, Arabana, Diyari. )

b. The target of preoralization is frequently a long consonant, either underlyingly geminate (Lappish, Icelandic) or geminated by rule (Arabana, Diyari). If non-geminate, the target may well be phonetically long: all other cases occur in final syllables, where the nasal is subject to final lengthening or lengthening under stress.

c. Preoralization is frequently accompanied by prestopping of laterals: $1->\mathrm{dl}$ in final syllables, and/or in geminate clusters (Halang, Mal, Stieng, Arabana, Diyari, Icelandic.)

d. All preoralized nasals are either prevocalic (if geminate) or final, and hence can be assumed to be released.

e. There may exist instances of preoralization after nasal vowels: Stieng (Poser 1978).

It appears then that preoralization correlates strongly with length: the nasals subject to it are frequently geminate and, if non-geminate, occur wordfinally, where they could be suspected of being at least phonetically longer than their non-final counterparts. Preoralization is generally accompanied by prestopping of laterals: geminate or word-final l's are partially delateralized in the same contexts where geminate or word-final nasals are preoralized. Further, there are no cases of preoralization of the form shown in (23), where a short intervocalic nasal acquires an oral half from a preceding oral vowel.

(23) Unattested preoralizations: ama $\rightarrow a^{b} a^{<2>}$ or ama $->a b a$

This should in itself cast doubt on the validity of the assimilatory analysis in (20), since [+nasal] harmonies most frequently target intervocalic non-geminate consonants: why should the corresponding oralization harmony fail to occur?

A further indication that we're not dealing with orality assimilation is the existence of at least one language - Stieng, reported by Poser - in which the prestopping takes place after nasal as well as oral vowels: e.g. ãm $\rightarrow$ ãbm. The prestopped nasals of Stieng clearly do not arise via spreading orality.

However what I believe is decisive for the analysis of preoralization is the frequent association with lateral prestopping. Of the twelve languages seen by Poser or myself, fully six combine prestopping with delateralization. This is not what we expect from a rule that spreads orality. Three examples of languages where preoralization and delateralization are combined appear below. 
(24) Diyari (Austin 1981): stress on first syllable, preoralization/prestopping only in first syllable:

a. Preoralization: kani $\sim$ kadni, wana $\sim$ wadna, kanini $\sim$ kadnini, but nana (*nadna)

b. Prestopping of laterals: yula $\sim$ yudla, nulu $\sim$ nudlu, mula $\sim$ mudla

(25) Arabana (Hercus 1972): stress on first syllable, preoralization/prestopping in first syllable: $\mathrm{C}$ becomes geminated after the stressed $\mathrm{V}$ in Proto-Arabana.

a. Preoralization: dínna $\rightarrow$ dídna, gúnna $\rightarrow$ gúdna, wímma $\rightarrow$ wíbma, but náninda, máninda

b. Prestopping: nálla -> nádla, wálla -> wádla

(26) Icelandic (Einarsson 1945): preoralization/prestopping applies only to geminated stops, which occur only under stress. Pre-obstruent C's do not undergo this process.

a. Preoralization: brunn $\rightarrow$ brudn, einnri $->$ eidnri, thounn $\rightarrow>$ thoudn, mann, minna

[compare vani $->$ va:ni, lan $\rightarrow$ lau:n, sandur $\rightarrow$ [sandyr]

b. Prestopping: allur $\rightarrow$ adlyr, allra $\rightarrow$ adlra, hella $\rightarrow$ hedla, fjall $\rightarrow$ fjadl [compare alit $->$ au:lit, ol $\rightarrow$ o:l, allt [al:t], alls [al:s]

The observations made so far suggest several reasons not to view preoralization as spreading of [-nasal]. The connection of preoralization with stress/gemination suggests that the preoralized nasals are always long, whether or not recorded as such. If so, one contributing factor to preoralization could be the tendency to initiate more slowly a long gesture (Smith 1992), in this case velum lowering. Preoralization would in part result from the fact that the initial portion of the long closure tends to remain oral. More significant are, as noted, the instances of preoralization accompanied by prestopping of laterals. They indicate that the primary phenomenon is not assimilation of the nasal to the orality of the vowel: an account based [-nasal] spreading will not extend to the lateral cases. Rather, what unifies preoralization and prestopping is (non-assimilatory) obstruentization. Why are stressed codas obstruentized? Edwards and Beckman (1988) suggest that stress induces a hypercharacterization of the sonority contrasts within the syllable: in this case, the sonority contrast is being exaggerated by turning the coda consonant into an obstruent. A related factor may be the tendency to strengthen (i.e. reduce sonority) of geminates. In the cases discussed here, the obstruentization is only partial and affects the essential portion of the geminate stop: its closure. Instances of full geminate strengthening include the Berber stopping of geminate fricatives $(\theta \theta \rightarrow \mathrm{tt}$, $66 \rightarrow$ $\mathrm{kk}$ ) and the North Germanic, and Fula stopping of geminate glides (yy $\rightarrow$ ggy, ww $\rightarrow$ ggw).

What is then the statement of preoralization? We take the central phenomenon to be obstruentization and write (27): the long (moraic) closure of a sonorant loses its association to the features that render it a sonorant, chiefly [nasal] and [lateral]. The sonorancy-inducing features remain associated to the (non-moraic) release, probably as a means of ensuring that the underlying features will be recoverable in the phonetic output. This recoverability clause explains the restriction to nasals occurring in prevocalic or word-final position, i.e. a position where they may preserve their release. Obstruentization of an unreleased nasal - 
a plain $A_{0}$ linked to [nasal] - would necessarily eliminate [nasal] from the representation.

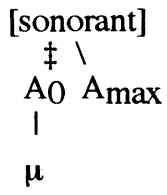

Language specific restrictions will have to be added to (27), in the form of parameters such as: (a) Does the rule apply to laterals ? (b) Is it limited to coronals? (c) Does it affect underlying long sonorants only or also sonorants lengthened derivationally ? But the core of the phenomenon can be securely identified as the loss of sonorancy in the coda. This is not orality assimilation.

\section{Conclusions and speculations}

Having disposed of all reasons to maintain [-nasal], we conclude that phonetic orality does not possess a phonological mark.

Why doesn't it ? Other articulatory dimensions - such as the tongue root movement $\langle 3\rangle$, the abducted or adducted position of the vocal cords $\langle 4\rangle$, and many others - have at least two corresponding phonological values. Let us compare only nasality, the clearly privative feature, and tongue root movement $(\mathrm{ATR})<5>$, the clearly equipollent one. We note that there exists a correlated difference in markedness patterns between them: when we factor out enhancement relations - such as the role of nasality as an auxiliary feature in the voicing of non-continuants - [nasal] segments always imply the presence of the corresponding oral ones, in all segment inventories. In contrast, neither [+ATR] nor [-ATR] segments imply the other class cross-linguistically: either category may be found without the other, or both simultaneously in the same system (Ladefoged and Maddieson 1990). There is - pace Kiparsky 1985, Archangeli and Pulleyblank 1989 - no reason to assume that tongue root advancement is the marked or the unmarked position relative to tongue root retraction. Advancement or retraction may be unmarked when in combination with other features - such as height - but not by themselves. This is not the case with nasality: as noted, nasal sounds always imply the corresponding oral ones.

We may hypothesize then that features like nasality - and others, such as those listed in (4) above - display context-free markedness because they are privative. And, correspondingy, that features like ATR - whose values may be marked or not only in combination with other feature values - lack context-free markedness because they are equipollent. It remains to understand why distinctive features might differ in such ways.

The observations made here suggest the following conjecture: there exists a neutral position, in the sense of SPE (Chomsky and Halle, 1968:300). Gestures involving a deviation from the neutral position carry a linguistic mark, i.e. a feature specification. Absence of deviation along some dimension results in absence of specification for the corresponding feature. Some articulatory dimensions are inherently asymmetric, in that only one perceptually salient deviation from the neutral position is possible: the example discussed here has been velum lowering or, equivalently, nasal airflow. Other possible examples may be lip pursing, which corresponds to the arguably privative feature [round] 
(Steriade 1987). Other articulatory dimensions are inherently symmetric, in that the neutral position is so located as to permit two opposite deviations: the tongue root may be neutral, advanced or retracted, the tongue body may be neutral, backed or fronted. Since two distinct deviations from the neutral position are possible, the relevant articulatory dimension corresponds to two equally marked feature values. Tongue root retraction and advancement should therefore correspond to two marked specifications, say ATR and RTR. Markedness can be equated then, in the articulatory domain, with deviation from this yet to be defined neutral position. Phonologically speaking, markedness is encoded simply by assigning the articulation that deviates from neutrality some corresponding feature. The unmarked articulation carries none.

\section{Footnotes}

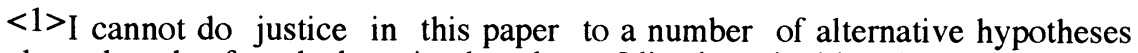
about the role of markedness in phonology. I list them, inviting the reader to infer from the following discussion why they are not being explored further. One possibility is that [-nasal] is an available feature value, but that it is unmarked relative to [+nasal]: one could hypothesize that only marked values give rise to assimilation/dissimilation. A related possibility is that [-nasal], the unmarked value, is absent in underlying representations precisely because it is unmarked (cf.Kiparsky 1985 on this connection between markedness and underspecification): perhaps long-distance assimilation and dissimilation apply to relatively early, maximally underspecified stages in the derivation, where [-nasal] is absent. This assumption, however, makes it almost impossible to detect the active presence of [-nasal] in the phonological representations: it then becomes imperative to show that [-nasal] values are needed at all. With respect to the absence of orality dissimilations, one may also consider the applicability of Ohala's (1981) general scenario for dissimilation to sequences of oral segments: perhaps listeners will seek a non-local source for a given feature value only when that value is marked and hence unexpected. If [-nasal] is the unmarked value, no listener will need to assume that a given sound is [-nasal] by assimilation to some other sound, since [-nasal] is the a priori expected value. All these hypotheses bank on the markedness difference between [+nasal] and [nasal], but leave unexplained the central issues: How is the difference in markedness between nasality and orality encoded in representations? If orality is unmarked why is it represented at all? What is the effect of markedness on rules: why should only marked features spread or appear underlyingly? Further discussion of this subject appears in Steriade (forthcoming).

$<2>$ Kaingang and Apinayé (Anderson 1976 and refs. there) are not instances of a phonological process turning ama into $a^{b}$ ma. These are languages with distinctively nasal vowels where the prestopping of $\mathrm{m}$ after oral vowels is an instance of "environmental shielding" (Herbert 1986): the nasal gesture is phonetically delayed to prevent a coarticulatory effect on preceding vowel. A coarticulatorily nasalized vowel will jeopardize, in such languages, the contrast between lexically oral and lexically nasal vowels. Guaraní falls into a distinct class of cases, since only its stressed vowels can be nasal: the lexical contrast between nasal and oral vowels is safeguarded in Guaraní too, as nasal harmony applies only within the foot. Further analysis of Apinayé and Kaingang nasality appears in Steriade (1992).

<3> On two-valued ATR see Archangeli and Pulleyblank 1989, Pulleyblank 1992). 
$<5>$ ATR is a misnomer for this feature, since it refers to advancement only. So is the alternative RTR or CP (Constricted Pharynx). The right name would be TRM: tongue root movement. I continue to employ standard terminology, so that references to other linguists' works will be intelligible.

\section{References}

Anderson, S.R. 1976 Nasality and the internal structure of segments, Language, $52,326-344$.

Archangeli, D. and Pulleyblank, D. (1989) Yoruba Vowel Harmony.

Linguistic Inquiry 20, 173.

Austin, P. 1981 A Grammar of Diyari, South Australia, Cambridge U Press.

Avery, P. and K.Rice 1989 Segment structure and coronal underspecification. Phonology, 179-201

Bendor-Samuel, T. 1960 Some problems of word segmentation in Terena. Word 16, 348-355

Cohn, A. 1990 Phonetic and Phonological Rules of Nasalization, UCLA PhD Dissertation, UCLA WPP \# 76.

Cohn, A. 1993 The status of nasalized continuants. To appear in M.Huffman and R.Krakow (eds.)Nasality Academic Press.

Court, C. 1967 A Distinctive feature analysis of phonemes in Mentu Land Dayak. Phonetica 17, 193-202

Edwards, J. and M.Beckman Articulatory Timing and Prosodic Interpretation of Syllable Duration. Journal of Phonetics, 45, 156

Einarsson, S. Icelandic, Grammar and Texts, The Johns Hopkins Press.

Flemming, E. 1993 The role of metrical structure in segmental rules. UCLA MA thesis.

Gomez-Imbert, E. 1980 La nasalité en Tatuyo. Amerindia 5, 65-81

Hercus, L. 1972 The Pre-Stopped Nasal and Lateral Consonants of ArabanaWangarungu. Anthropological Linguistics, 14, 293-305.

van der Hulst, $H$. and N.Smith 1982 Prosodic domains and opaque segments in autosegmental theory. in H. van der Hulst and N.Smith (eds.) The Structure of Phonological Representations, vol. 2, p.311-336.

Herbert, R.K. 1986 Language universals, markedness theory and natural phonetic processes, de Gruyter, Berlin.

Kaye, J. 1971 Desano nasal harmony. Linguistic Inquiry 2, 37-56

Kenstowicz, M. and C.Kisseberth 1978 Generative Phonology, Academic Press, Orlando.

Kingston, J. 1985 The Phonetics and Phonology of the Timing of Oral and Glottal events, University of California, Berkeley, Ph.D. Diss.

Kiparsky, P. 1985 Some consequences of Lexical Phonology. Phonology 
Yearbook 2, 85-138.

Ladefoged, P. 1971 Preliminaries to Linguistic Phonetics, U of Chicago Press.

Ladefoged and Maddieson 1990 Vowels of the world's languages.Journal of Phonetics 18, 93-122

Maddieson, I. 1984 Patterns of Sounds, Cambridge Studies in Speech Science and Communication.

Ohala, J. 1975 Phonetic explanations for nasal sound patterns. in C.Ferguson, L.Hyman and J.Ohala (eds.) Nasálfest: Papers from a symposium on nasals and nasalization. Language Universals Project, Stanford University.

Ohala, J. 1981 The Listener as a Source of Sound Change. A.Cohen and M.P.R.V. van der Broecke (eds.) Abstracts of the 10th International Congress of Phonetic Sciences, p.252-258, Dordrecht.

Pike, K. and E.Pike 1947 Immediate constituents of Mazateco syllables. InternationAl Journal of American Linguistics, 13, 78-91.

Poser, W. 1978 Nasal Contour Consonants and the Concept of Segment, Harvard BA thesis.

Poser, W. 1981 Nasal stops and nasal fricatives, ms. MIT.

Piggott, G. 1992 Variability in feature dependency: the case of nasality. Natural Language and Linguistic Theory 10, 33-78

Pulleyblank, D. 1989 Patterns of Co-Occurrence: the Case of Nasality. ms. University of Ottawa.

Pulleyblank, D. 1992 Feature geometry and underspecification. to appear in vol. edited by J.Durand and F.Katamba.

Rivas, A. 1975 Nasalization in Guarani. NELS 5, Harvard University, Linguistics Dept.

Scott, N.C. 1964 Nasal Consonants in Land Dayak. in D.Abercrombie (ed.) In Honour of Daniel Jones, Longmans.

Smith, C. 1992 The Timing of Vowel and Consonant Gestures, Yale Ph.D. Dissertation

Steriade, D. 1987 Redundant values. in A.Bosch, B.Need and E.Schiller (eds) Papers from the 23rd CLS: Parasession on Metrical and Autosegmental Phonology, University of Chicago.

Steriade, D. 1993 Closure, release and nasal contours. To appear in M.Huffman and R.Krakow (eds.)Nasality Academic Press.

Steriade, D. (forthcoming) Underspecification and markedness. ms. UCLA.

Trigo, L. 1992 Paper to appear in M.Huffman and R.Krakow (eds.) Nasality: Academic Press.

Zsiga, L. 1992 A mismatch between morphological and prosodic domains. Phonology, 9, 101-135 